\title{
Case Study on the Use of Microcurrent Therapy in Regeneration of an Arthritic Hip Due to Side Effect of Steroid for Treatment of Teenage Acnes Vulgaris
}

\author{
Milly Ng* \\ Body Rejuvenation Consultant \\ *Corresponding author: Milly Ng, Body Rejuvenation Consultant
}

Submission: 䙲February 08, 2019; Published: 眥February 27, 2019

\begin{abstract}
It is a firm belief in modern medicine that Joint cartilage once damaged, torn or degenerated, there is no chance of recovery. The only solution would be joint replacement. This case study show evidence in the pre and post treatment $\mathrm{X}$ ray findings that Microcurrent can reverse the inflammation and bring the original compressed joint space back to normal which highly suggest the cartilage has grown back to occupy the joint space given that patient enjoy pain free mobility of normal daily activities including walking, running and stairs.
\end{abstract}

\section{Introduction}

Mr. Lee (fake name) was 39 years old, father of a one-year old baby boy with Torticollis since birth. Baby had Physiotherapy at one of the government hospitals with little progress over the year. So, Lee decided to seek Microcurrent treatment for the baby as recommended by a friend with similar issue. In 10 days, baby was fully recovered [1]. Amazed by the result, Lee asked Milly the therapist if Microcurrent can help regenerate his left Arthritic Hip which affected his daily living- pain even on level ground walking, increase pain with stairs and running, not to mention his favorite ball room dance. Lee has scheduled for a Total Hip Replacement surgery in one week's time. He was very keen to know if the treatment can help to regenerate the joint to spare him from the surgery, as he was told the artificial joint can only last about 10 years, which means every 10 years he must go under the knife unless there are other new method to combat this condition (Figure 1).

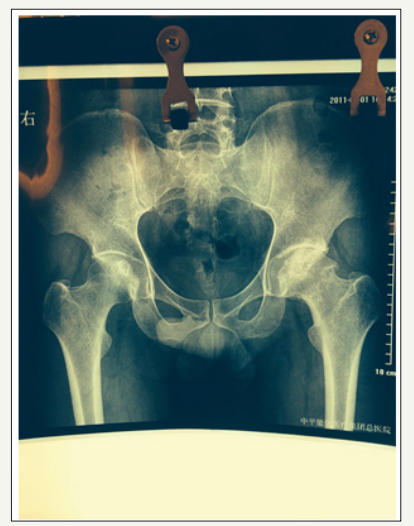

Figure 1: X ray of bilateral hip taken in 2011.
Lee was from mainland China. 20+ years ago when he was a teenager, he had unsightly Acnes Vulgaris so was prescribed heavy dose of Steroid to treat the Acnes. He said it was very prevalent to use Steroid at that time and a lot of his friends are also having similar side effect of Arthritic hips. On examination, Lee's affected left Hip joint was limited at end range of flexion for $10^{\circ}$ compare to right side. He can walk on level ground without much limping. There was pain on weight bearing phase over left leg in walking. Any quick movement, running, turning etc. will elicit sharp pain.

A course of 10 sessions of microcurrent therapy was started

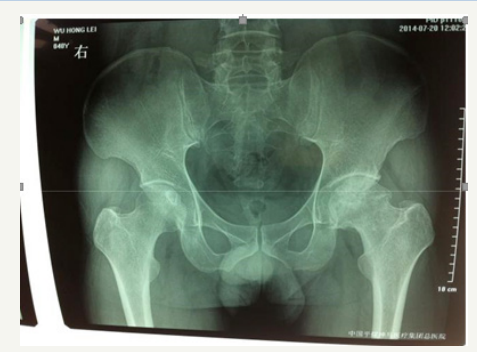

Figure 2: X ray of bilateral hip taken on July 20,2014 right after finished the course of Microcurrent Therapy.

On Day 1 after the first treatment (45min), Lee was so confident that he sprinted in the carpeted corridor of my Central Clinic as if there is nothing wrong with his hip. On further detailed examination, the joint range was full range in all directions and pain free, including flexion which was limited at end range with pain before treatment. He cannot run and limp to go up and down steps and would not be able to move fast nor have any abrupt movement 
before treatment. I was very surprised that he can run as if he was normal after treatment (Figure 2).

After completed the whole course, Lee felt pain free and can walk without pain, can run and managed steps going up and down without any difficulty. Range of movement was full without pain.

\section{The scheduled surgery was cancelled}

Lee returned to China, sent X-ray of the Hip took on July 20, 2014 and forwarded the old X ray taken in 2011 for comparison (Figure $1 \& 2$ ). One can see significant improvement of the joint line and increased of joint space to normal which means the cartilage has been regenerated to fill up the joint space.

\section{Conclusion}

Microcurrent can be used to regenerate the Arthritic Hip reduce inflammation and regenerate the cells of the joint rendering it become normal so can defer the operation, at least to a much older age. The opinion of cartilage worn out or degenerated would not be able to regenerate and must be corrected with surgery might need to be reviewed.

\section{References}

1. Milly Ng (2014) Case Study from Central Physiotherapy \& Sports Injury Clinic, Central Hong Kong, China.
Creative Commons Attribution 4.0

International License

For possible submissions Click Here
Submit Article

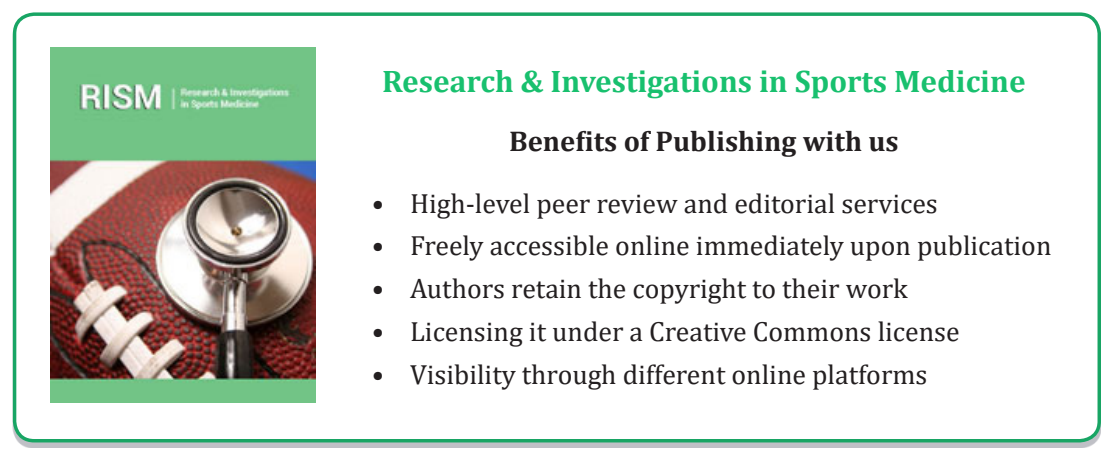

